\title{
Relationship between emotional states before cardiac valve surgeries with postoperative complications
}

\author{
Relações entre o estado emocional antes da cirurgia cardíaca
}

valvar com complicações no pós-operatório

Relaciones entre el estado emocional antes de la cirugía cardíaca valvar con complicaciones en el post-operatorio

\section{Hélen Francine Rodrigues ${ }^{a}$ \\ Rejane Kiyoma Furuyab \\ Rosana Aparecida Spadoti Dantas ${ }^{c}$ \\ Rafaela Dias Coloni Morelato ${ }^{c}$ \\ Carina Aparecida Marosti Dessotte}

\section{How to cite this article:}

Rodrigues HF, Furuya RK, Santas RAS,

Morelato RDC, Dessotte CAM. Relationship between emotional states before cardiac valve surgeries with postoperative complications. Rev Gaúcha Enferm. 2020;41:e20190025. doi: https://doi. org/10.1590/1983-1447.2020.20190025 a Hospital Unimed Ribeirão Preto. Ribeirão Preto, São Paulo, Brasil.

• Instituto Federal do Paraná (IFPR), Campus Londrina Londrina, Paraná, Brasil.

Universidade de São Paulo (USP), Escola de Enfermagem de Ribeirão Preto, Centro Colaborador da OPAS/OMS para o Desenvolvimento da Pesquisa em Enfermagem, Ribeirão Preto, São Paulo, Brasil.

\section{ABSTRACT}

Objective: To investigate associations between preoperative anxiety and depression symptoms and postoperative complications and the sociodemographic and clinical characteristics of patients undergoing valve repair surgery.

Method: Observational, exploratory and prospective study. The consecutive non-probabilistic sample consisted of patients undergoing their first valve repair surgery. Data were collected from September 2013 to September 2015, in a university hospital in the interior of São Paulo, Brazil. Symptoms were assessed using the Hospital Anxiety and Depression Scale and analyzed using MannWhitney and Spearman correlation; alpha was established at $5 \%$

Results: Among the 70 participants, depressive symptoms were more frequent among women $(p=0.042)$ and among patients experiencing postoperative agitation $(\mathrm{p}=0.039)$

Conclusion: In this study, depressive symptoms were associated with being a woman and postoperative agitation; the same was not true in regard to anxiety symptoms.

Keywords: Anxiety. Depression. Thoracic surgery.

\section{RESUMO}

Objetivo: Investigar a associação dos sintomas de ansiedade e depressão pré-operatórios com complicações no pós-operatório e com características sociodemográficas e clínicas de pacientes submetidos à correção cirúrgica de valvopatias.

Método: Estudo observacional, exploratório e prospectivo. Uma amostra consecutiva e No probabilística foi constituída por pacientes submetidos à primeira cirurgia de correção de valvopatias. Os dados foram coletados de setembro/2013 a setembro/2015, em um hospital universitário do interior paulista. Os sintomas foram avaliados pela Hospital Anxiety and Depression Scale. Os dados foram analisados pelos testes de Mann-Whitney e Correlação de Spearman, alpha de 5\%.

Resultados: Entre os 70 pacientes, encontrou-se maior presença de sintomas depressivos entre as mulheres $(p=0,042)$ e no grupo com agitação $(p=0,039)$ no pós-operatório.

Conclusão: No grupo estudado, sintomas depressivos foram associados ao sexo feminino e a agitação no pós-operatório, o que № ocorreu com os sintomas de ansiedade.

Palavras-chave: Ansiedade. Depressão. Cirurgia torácica.

\section{RESUMEN}

Objetivo: Investigar la asociación de los síntomas de ansiedad y depresión preoperatorios con complicaciones en postoperatorio y con características sociodemográficas y clínicas de pacientes sometidos a la corrección quirúrgica de valvopatías.

Método: Estudio observacional, exploratorio y prospectivo. Muestra consecutiva y no probabilística fue constituida por pacientes sometidos a la primera cirugía de corrección de valvopatías. Los datos fueron recolectados de septiembre/2013 a septiembre/2015, en un hospital universitario del interior del São Paulo. Los síntomas fueron evaluados por el Hospital Anxiety and Depression Scale. Los datos fueron analizados por las pruebas de Mann-Whitney y Correlación de Spearman, alpha=5\%.

Resultados: Entre los 70 pacientes, fue encontrado mayor presencia de síntomas depresivos entre las mujeres $(p=0,042)$ y en el grupo con agitación $(p=0,039)$ en el postoperatorio.

Conclusión: En el grupo estudiado, los síntomas depresivos se asociaron al sexo femenino y la agitación en el postoperatorio, lo que no ocurrió con los síntomas de ansiedad.

Palabras clave: Ansiedad. Depresión. Cirugía torácica. 


\section{口INTRODUCTION}

Major surgeries have been associated with high levels of anxiety and depression ${ }^{(1-2)}$, while the wait for cardiac surgery evokes even greater levels of stress than other types of complex surgeries ${ }^{(3)}$. In addition to personal factors such as pain and distress, other factors associated with the anesthetic-surgical process and potential postoperative complications have been shown to be the causes of symptoms of anxiety in the time leading up to a surgical procedure ${ }^{(3)}$.

Preoperative anxiety and depression symptoms have been associated with increased morbidity and mortality after cardiac surgeries ${ }^{(4)}$. These symptoms experienced in the preoperative period may trigger a physiological response involving the endocrine and autonomic systems that influence the postoperative outcome, increasing the risk of complications and length of hospitalization ${ }^{(5)}$.

Individuals with valve disease undergoing surgical repair are the focus of this study. This surgical intervention consists of reconstructing or replacing the affected valve in order to relieve symptoms and restore the patients' physiological hemodynamics. In Brazil, rheumatic fever represents a significant share of Cardiovascular Diseases (CVD), accounting for up to $70 \%$ of valve disease cases, which may result in cardiac dysfunction and death ${ }^{(6)}$.

Interventional cardiology has made significant advances in recent years in the treatment of aortic and mitral valve diseases. Transcatheter aortic valve implantation (TAVI) and the percutaneous treatment of mitral regurgitation (clip implant in the leaflets) have been considered safe approaches to treat aortic stenosis and mitral regurgitation, respectively ${ }^{(7)}$. Both TAVI and clip implantation are treatments usually reserved for elderly patients with a high surgical risk ${ }^{(7-8)}$ and in most cases are performed oversees, though these minimally invasive procedures tend to be increasingly common in Brazil.

Researchers monitored patients with aortic stenosis and compared a group of patients undergoing TAVI with a group of patients undergoing conventional surgery and verified that surgically treated symptomatic patients reported higher levels of anxiety and depression ${ }^{(8)}$, indicating there is a need to check the emotional states of patients awaiting valve surgeries.

Despite all the progress achieved in percutaneous and surgical treatments with improved surgical techniques and postoperative care, cardiac surgeries remain the treatment of choice for a large number of patients who have potential complications that increase postoperative morbidity and mortality ${ }^{(9)}$.

In recent decades, candidates for surgical valve repair have seen a considerable increase in severe conditions. A change in the profile of patients with valve diseases has been observed, with patients of advanced age, presenting double valve lesion, reduced left ventricular ejection fraction (LVEF), and associated comorbidities and complications, such as pulmonary hypertension and atrial fibrillation, which combine to increase a patient's surgical risk ${ }^{(10)}$.

In addition to involving physiopathological aspects, the simple fact that cardiac surgery is the indicated treatment may be a stressful event by itself and trigger intense emotional responses in patients, possibly leading to various psychological manifestations, especially symptoms of anxiety and depression ${ }^{(9)}$.

Even though recovery after valve surgery is influenced by preoperative factors (e.g., left ventricular ejection fraction and kidney function) and intraoperative factors (e.g., myocardial ischemia that results in ventricular impairment and type of surgical approach), psychological and emotional implications should be considered in the recovery process ${ }^{(11)}$.

In this context, nurses need technical-scientific knowledge regarding the physiopathology of the psycho-emotional stressors involved, such as anxiety and depression, in order plan the perioperative nursing care to be provided to those with valve disease. The early identification of these symptoms, as well as an understanding of how they influence a patient's clinical situation, enables appropriate nursing interventions that favor patient recovery.

The literature reports the presence of anxiety and depression symptoms in the pre- and postoperative period of cardiac surgeries, while anxiety is most predominant in the preoperative period. Even though depression symptoms may occur before a surgery, they are most frequent in the postoperative ${ }^{(12)}$. Previous studies, however, have focused on the presence of anxiety and depression symptoms among patients exclusively undergoing coronary artery bypass grafting $^{(1,13)}$.

Given the previous discussion, this study's objective was to investigate whether there is a relationship between preoperative anxiety and depression symptoms with postoperative complications among patients undergoing their first valve repair surgery while hospitalized in an Intensive Care Unit (ICU), as well as to assess potential associations between anxiety and depression symptoms with the sociodemographic and clinical characteristics of these patients.

\section{DETHOD}

This prospective, longitudinal, observational and exploratory study originated from a Master's thesis. It was conducted at the Medical and Surgical Inpatient Unit of a university hospital in the interior of São Paulo, Brazil. Because 
there was a lack of information regarding complication rates and emotional states of the target population assessed through the Hospital Anxiety and Depression Scale (HADS), a sample size was not calculated for this study, which is the reason for its exploratory nature. This study's results can be used in the future to calculate the appropriate number of preoperative patients with valve diseases, which is necessary to verify whether a patient's emotional state is related to the presence of the main postoperative complications that take place in an ICU.

Thus, the consecutive and non-probabilistic sample was composed of patients who met the inclusion criteria: both sexes, aged 18 years old or older, undergoing their first valve repair surgery, with elective scheduling (more than 12 hours in advance).

Data were collected by a Master's student, using pilot questionnaires, after being trained by her advisor and under the advisor's supervision, from September 2013 to September 2015.

Patients lacking the cognitive condition to answer the questionnaires or presenting clinical decompensated heart failure on the day of the preoperative data collection (presence of dyspnea, chest pain or orotracheal intubation) were excluded. Patients whose data were not fully collected (in both the pre- and postoperative periods) due to death in the surgical room were withdrawn.

The Brazilian version of the Mini-Mental State Exam (MMSE) ${ }^{(14)}$ was used to identify patients possessing the cognitive condition to answer the questionnaires. The following cutoff points were adopted in this study: illiterate patients were supposed to score at least 13 points; those with seven years of schooling were supposed to score a minimum of 18 points; and a score of at least 26 points was required from those with eight or more years of schooling ${ }^{(14)}$.

Data were collected through individual interviews and from the participants' medical charts. Additionally, sociodemographic and clinical information, along with information concerning anxiety and depression symptoms, was collected on the day preceding their surgery. Twenty-four hours, at most, after patients were discharged from the ICU, data related to their postoperative progression and whether there were complications, were collected from the patients'files at the Surgical Inpatient Unit, or from the hospital's electronic data system. The patients' clinical progression, assessed by the medical and nursing staff and reported via the instruments used to monitor patients with valve disease in the postoperative period, was analyzed.

In this study, postoperative period refers to the time patients remain in the ICU, that is, from the time they were admitted to this unit immediately after surgery up to the time they were discharged from the ICU.

An instrument based on a literature review and a previous study ${ }^{(15)}$ was developed to characterize the participants. It addressed sociodemographic data (date of birth, dates of hospitalization and interview, sex, marital status, schooling, occupation, and monthly family income) and clinical data (type of valve heart disease, comorbidities, LVEF, smoking, and the preoperative use of psychotropic drugs). This instrument was submitted to face and content validation by a judge committee with extensive experienced in cardiology and cardiovascular surgeries.

LVEF equal to or greater than $50 \%$ were considered normal and lower than $50 \%$ were considered low ${ }^{(12)}$, according to the parameters used in this hospital facility.

The following postoperative data were collected in the ICU: day and time of admission to the ICU, day and time the endotracheal tube (ETT) was removed, lactate values, diuresis volume, central venous oxygen saturation, postoperative evolution (mean blood pressure, central venous pressure, serum creatinine levels), death or day and time of ICU discharge. The length an ETT was used was calculated by subtracting the day and time it was removed from the day and time the patient was admitted to the ICU. The length patients stayed at the ICU was calculated by subtracting the day and time of discharge from the day and time of admission. The results concerning serum lactate and central venous oxygen saturation were collected from the hospital's electronic data system.

Complications were listed based on the physiological response triggered by the anesthetic-surgical procedure and the aforementioned studies in which preoperative anxiety and depression symptoms are considered additional stressors among patients undergoing cardiac surgeries. We investigated the presence of: pulmonary complications (tracheal intubation under mechanical ventilation lasting more than 48 hours after surgery); cardiac complications (presence of hemodynamic instability); neurological complications (presence of neurosensory deficit and/or agitation); endocrine complications (hyperglycemia - plasma glucose above $100 \mathrm{mg} / \mathrm{dl}^{(16)}$; infectious complications (diagnosis of urinary tract infection, health care-associated pneumonia, bloodstream infection or surgical site infection); digestive complications (nausea and vomiting); sensorial complication (pain); and death in the postoperative period during ICU stay.

The presence of postoperative infection was confirmed by information concerning hospital infection available from the Hospital Infection Control Commission (ICC). 
In order to characterize the patients in terms of hemodynamic stability (stable or unstable), in this study we used tissue perfusion biomarkers, in the belief that the most important objective of monitoring and maintaining hemodynamic stability is to ensure target-organs perfusion. From a clinical perspective, one should aim to maintain mean blood pressure above $70 \mathrm{mmHg}$, satisfactory level of consciousness, and appropriate diuresis (>0.5 mL/kg/hour). From a biochemical point of view, the most frequently used markers are serum lactate and central venous oxygen saturation ${ }^{(17)}$. Participants were classified as having "hemodynamic instability" when concomitant changes were identified in three of the parameters described, at any point of the ICU stay, regardless of the frequency with which such a condition was observed.

The Portuguese version ${ }^{(18)}$ of the HADS was used to assess preoperative anxiety and depression symptoms. This instrument contains 14 questions (seven addressing anxiety and seven depression), which assess somatic and psychological symptoms on a four-point Likert scale. The scores range from zero to three, while the score for each of the emotional disorders ranges from zero to 21 (twenty-one) points. In this study, the responses were analyzed considering the total score of each subscale (HADS anxiety and HADS depression); the higher the score, the greater one's perception of anxiety and depression symptoms.

The non-parametric Mann-Whitney test (to compare differences between two independent samples) was used to verify associations between preoperative anxiety and depression symptoms and the presence or absence of postoperative complications during ICU stay and sex, age, marital status, and occupation. The test of hypothesis was performed when at least four of these parameters presented complications.

The Spearman correlation test was adopted to verify correlation between measured preoperative anxiety and depression symptoms with length of preoperative hospitalization and ICU stay. The following classification was adopted to analyze the magnitude of linear correlations between measures: values below 0.30 were considered to have no clinical relevance, even when statistically significant; between 0.30 and 0.50 indicate moderate correlation; and above 0.50 indicate strong correlation ${ }^{(19)}$. The level of significance was set at 0.05 .
The study project was in accordance with the ethical principles recommended by Resolution 466/2012 and approved by the Institutional Review Board at the University of São Paulo at Ribeirão Preto, College of Nursing (Opinion report No. 191/2013). The patients were invited to participate in the study and, after providing their consent, signed two copies of free and informed consent forms (one copy was kept by the participant and the other was filed by the researcher)

\section{Q RESULTS}

A total of 296 cardiac surgeries (myocardial revascularization surgery, valve repair surgeries, and aortic disease surgeries) were performed between September 2013 and September 2015. Of these, 70 patients met the inclusion criteria and agreed to participate in the study.

Most participants were male ( $n=43 ; 61.4 \%)$, married or in consensual union ( $n=51 ; 72.9 \%)$, and did not have a paid job before the surgery $(n=48 ; 68.6 \%)$. The participants were 54.4 years old on average $(S D=12.8)$, ranging from 25 to 87 years old, and had 5.1 years of schooling on average $(S D=3.8)$, while the mean monthly family income was $\mathrm{R} \$ 1,988.8$ (Brazilian Reais) ( $S D=1,242.9$ ).

The patients' preoperative clinical characterization is presented in Table 1.

Preoperative LVEF was considered normal in 56 (80.0\%) patients, while 14 (20.0\%) presented reduced LVEF. The average hospitalization of patients in the preoperative period was 13.0 days ( $S D=9.1$; median $=9.5$ ), ranging from one to 40 days.

Regarding the results of anxiety and depression symptoms, the patients presented a mean of 5.3 ( $S D=4.2$; median of 4.0) for anxiety symptoms, ranging from zero to 20.0 and a mean of 3.7 (SD=3.8; median of 3.0) for depression symptoms, ranging from zero to 15.0 .

Characterization of the patients' postoperative complications is presented in Table 2. The most frequent complications were: hyperglycemia, in $92.9 \%$ of the patients; pain (81.4\%) and hemodynamic instability (61.4\%).

The average length of ICU stay was 3.5 days $(S D=2.3)$, ranging from one to 13 days (median=3.0).

The results concerning comparisons of anxiety and depression measures, according to the presence of complications, are presented in Table 3. 
Table 1 - Clinical characterization of patients undergoing valve repair surgery according to the type of valve disease, comorbidities, lifestyle, and use of psychotropic drugs ( $n=70)$. São Paulo, Brazil, 2013-2015

\begin{tabular}{|c|c|}
\hline Variables & n (\%) \\
\hline \multicolumn{2}{|l|}{ Type of valve disease } \\
\hline Stenosis + Insufficiency & $33(47.1)$ \\
\hline Insufficiency & $24(34.3)$ \\
\hline Stenosis & $10(14.3)$ \\
\hline Not reported in the medical chart & $3(4.3)$ \\
\hline \multicolumn{2}{|l|}{ Comorbidities } \\
\hline Systemic Blood Pressure & $41(58.6)$ \\
\hline Overweight/Obesity & $34(48.5)$ \\
\hline Dyslipidemia & $25(35.7)$ \\
\hline Heart failure & $23(32.9)$ \\
\hline Atrial fibrillation & $14(20.0)$ \\
\hline Diabetes Mellitus & $12(17.1)$ \\
\hline \multicolumn{2}{|l|}{ Lifestyle } \\
\hline Prior smoking & $30(42.9)$ \\
\hline Current smoking & $12(17.1)$ \\
\hline \multicolumn{2}{|c|}{ Use of preoperative psychotropic drugs } \\
\hline Yes & $13(18.6)$ \\
\hline
\end{tabular}

Source: Research data, 2015.

Table 2 - Postoperative complications among patients undergoing valve repair surgery (n=70). São Paulo, Brazil, 2013-2015

\begin{tabular}{lll} 
& \multicolumn{1}{c}{ Variables } & n (\%) \\
\hline Endocrine & Presence of Complications & $65(92.9)$ \\
\hline Sensory & Hyperglycemia & $57(81.4)$ \\
\hline Heart & Pain & $43(61.4)$ \\
\hline Digestive & Hemodynamic instability & $29(41.4)$ \\
\hline Neurological & Nausea & $16(22.9)$ \\
\cline { 2 - 3 } & Vomiting & $17(24.3)$ \\
\hline Pulmonary & Agitation & $4(5.7)$ \\
\cline { 2 - 3 } Death & Neurosensory & $9(12.9)$ \\
\hline Infectious diseases & ETTa beyond 48 hours & $5(7.1)$ \\
\hline & Yes & $3(4.3)$ \\
\hline
\end{tabular}


Table 3 - Descriptive analysis of anxiety and depression symptoms of 70 patients undergoing valve repair surgery according to postoperative complications ( $n=70)$. São Paulo, Brazil, 2013-2015

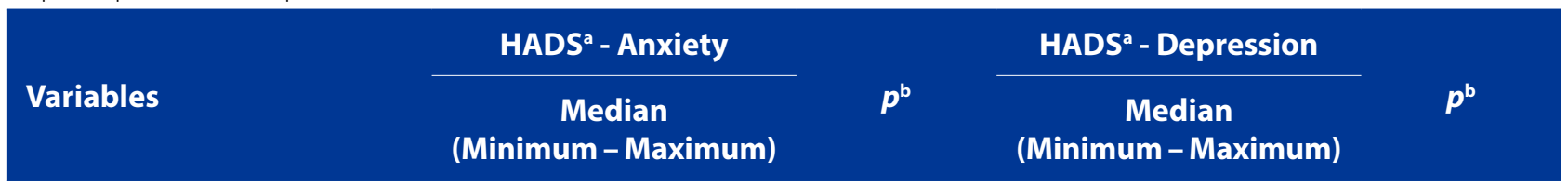

\section{Hyperglycemia}

$\begin{array}{ccccc}\text { Yes }(n=65) & 4.0(0-20) & 0.679 & 3.0(0-15) & 0.564 \\ \text { No }(n=5) & 4.0(1-9) & 4.0(0-13)\end{array}$

\section{Pain}

\begin{tabular}{|c|c|c|c|c|}
\hline Yes $(n=57)$ & $4.0(0-20)$ & 0.939 & $3.0(0-15)$ & 0.598 \\
\hline No $(n=13)$ & $6.0(0-9)$ & & $3.0(0-7)$ & \\
\hline
\end{tabular}

\section{Hemodynamic instability}

\begin{tabular}{lccc}
\hline Yes $(n=43)$ & $4.0(0-16)$ & 0.951 & $3.0(0-15)$ \\
\hline No $(n=27)$ & $4.0(0-20)$ & $3.0(0-12)$ \\
\hline Nausea & &
\end{tabular}

\begin{tabular}{ccccc}
\hline Yes $(n=29)$ & $4.0(0-20)$ & 0.768 & $3.0(0-13)$ & 0.814 \\
\hline No $(n=41)$ & $4.0(0-16)$ & $3.0(0-15)$ \\
\hline
\end{tabular}

\section{Agitation}

\begin{tabular}{|c|c|c|c|c|}
\hline Yes $(n=17)$ & $6.0(0-13)$ & 0.216 & $4.0(0-15)$ & 0.039 \\
\hline No $(n=53)$ & $4.0(0-20)$ & & $2.0(0-13)$ & \\
\hline \multicolumn{5}{|l|}{ Vomiting } \\
\hline Yes $(n=16)$ & $4.0(0-16)$ & 0.882 & $1.0(0-13)$ & 0.377 \\
\hline No $(n=54)$ & $4.0(0-20)$ & & $3.0(0-15)$ & \\
\hline
\end{tabular}

\section{$E T^{c}>$ than 48 hours}

\begin{tabular}{|c|c|c|c|c|}
\hline Yes $(n=9)$ & $6.0(0-9)$ & 0.951 & $4.0(1-10)$ & 0.218 \\
\hline $\mathrm{No}(\mathrm{n}=61)$ & $4.0(0-20)$ & & $3.0(0-15)$ & \\
\hline
\end{tabular}

\section{Death}

\begin{tabular}{|c|c|c|c|c|}
\hline Yes $(n=5)$ & $4.0(1-10)$ & 0.863 & $4.0(3-5)$ & 0.289 \\
\hline $\mathrm{No}(\mathrm{n}=65)$ & $4.0(0-20)$ & & $3.0(0-15)$ & \\
\hline \multicolumn{5}{|c|}{ Neurosensory deficit } \\
\hline Yes $(n=4)$ & $4.0(0-8)$ & 0.583 & $3.0(2-4)$ & 0.798 \\
\hline No $(n=66)$ & $4.0(0-20)$ & & $3.0(0-15)$ & \\
\hline
\end{tabular}

Source: Research data, 2015

HADS : Hospital Anxiety and Depression Scale; $p^{\mathrm{b}}$ : $p$-value of Mann-Whitney test; ETT: Endotracheal tube. 
The patients experiencing agitation obtained a greater median for depression symptoms when compared to patients who did not present this complication; the difference was statistically significant ( $p=0.039)$.

Table 4 presents the medians and minimum and maximum values of anxiety and depression symptoms according to the patients' sex, age, marital status, and occupation.

Women presented a greater median for anxiety and depression symptom than men, though the difference was significant only for depression symptoms ( $p=00.42)$.
Additionally, the maximum values obtained by the women for anxiety and depression symptoms were greater compared to those obtained by men.

The results concerning the correlations between anxiety and depression symptoms and clinical characteristics (length of preoperative hospitalization and length of ICU stay) are presented in Table 5.

The correlations between anxiety and depression symptoms and preoperative hospitalization and length of ICU stay were weak (below 0.30) and not statistically significant.

Table 4 - Descriptive analysis of anxiety and depression symptoms of patients undergoing valve repair surgery according to age, marital status, and occupation $(n=70)$. São Paulo, Brazil, 2013-2015

\begin{tabular}{|c|c|c|c|c|}
\hline \multirow[b]{2}{*}{ Variables } & HADS ${ }^{\mathrm{a}}$ - Anxiety & \multirow[b]{2}{*}{$\boldsymbol{p}^{\mathbf{b}}$} & HADS ${ }^{\mathrm{a}}$ - Depression & \multirow[b]{2}{*}{$\boldsymbol{p}^{\mathrm{b}}$} \\
\hline & $\begin{array}{c}\text { Median } \\
\text { (Minimum - Maximum) }\end{array}$ & & $\begin{array}{c}\text { Median } \\
\text { (Minimum - Maximum) }\end{array}$ & \\
\hline \multicolumn{5}{|l|}{ Sex } \\
\hline Male $(n=43)$ & $4.0(0-14)$ & 0.152 & $3.0(0-11)$ & 0.042 \\
\hline Female $(n=27)$ & $5.0(1-20)$ & & $4.0(0-15)$ & \\
\hline \multicolumn{5}{|l|}{ Age } \\
\hline Elderly $(\mathrm{n}=42)$ & $4.0(0-13)$ & 0.126 & $3.0(0-9)$ & 0.995 \\
\hline Adult ( $\mathrm{n}=28)$ & $4.5(0-20)$ & & $2.0(0-15)$ & \\
\hline \multicolumn{5}{|l|}{ Marital status } \\
\hline W/ a partner $(n=51)$ & $4.0(0-16)$ & 0.816 & $3.0(0-13)$ & 0.280 \\
\hline W/o a partner $(n=19)$ & $4.0(0-20)$ & & $4.0(0-15)$ & \\
\hline
\end{tabular}

\section{Occupation}

\begin{tabular}{llll}
\hline No paid job $(n=48)$ & $4.0(0-20)$ & 0.486 & $3.0(0-15)$ \\
\hline Paid job $(n=22)$ & $4.0(0-14)$ & $2.5(0-13)$ \\
\hline
\end{tabular}

Source: Research data, 2015.

HADS: Hospital Anxiety and Depression Scale; $p^{b}$ : p-value of Mann-Whitney test.

Table 5 - Correlation between anxiety and depression symptoms and preoperative length of hospitalization and length of ICU stay among patients undergoing valve repair surgery and respective probabilities ( $p$ ) associated with the Spearman correlation test. São Paulo, Brazil, 2013-2015

\begin{tabular}{|c|c|c|c|c|}
\hline Variables & \multicolumn{2}{|c|}{ HADS $^{a}$ - Anxiety } & \multicolumn{2}{|c|}{ HADSa - Depression } \\
\hline Clinical characteristics & $\mathbf{r}$ & $\boldsymbol{p}$ & $\mathbf{r}$ & $p$ \\
\hline $\begin{array}{l}\text { Length of preoperative } \\
\text { hospitalization (days) }\end{array}$ & -0.132 & 0.277 & -0.221 & 0.066 \\
\hline $\begin{array}{l}\text { Length of ICUb } \\
\text { stay (days) }\end{array}$ & 0.123 & 0.311 & 0.125 & 0.302 \\
\hline
\end{tabular}

Source: Research data, 2015.

HADS: Hospital Anxiety and Depression Scale; IC $U^{\text {b: }}$ Intensive Care Unit. 


\section{DISCUSSION}

Investigating whether patients who more frequently present preoperative anxiety and depression symptoms also more frequently present postoperative complications of valve repair surgeries while in ICU guided this study. This study's patients who presented more frequent preoperative symptoms, also more frequently presented postoperative agitation when compared to those who presented mild depressive symptoms; differences were statistically significant. On the other hand, no relationship was found between preoperative anxiety symptoms and complications. This finding contradicts findings reported by studies addressing anxiety among patients undergoing myocardial revascularization surgery ${ }^{(20)}$.

Comparison between this study's results and the literature is hindered considering no studies addressing relationships between preoperative anxiety and depressive symptoms and postoperative complications among patients, who exclusively underwent valve repair surgery during ICU stay, were found. This is a very relevant topic because the emotional symptoms of patients undergoing valve repair surgery are seldom explored.

Until recently, depression had not been assessed in regard to its association with mortality after cardiac surgeries in non-ischemic states, such as valve repair surgery. In this sense, a cohort study addressing 648 patients exclusively undergoing valve surgery in 14 Veteran Administration Hospitals considerably added to existing knowledge when it identified that one third of all patients awaiting valve surgery presented significant preoperative depressive symptoms. The authors concluded that preoperative depression was an independent risk factor for mortality after a cardiac valve surgery ${ }^{(21)}$. In this study, however, the patients presented mild preoperative depressive symptomatology.

No relationships were found between preoperative anxiety and depression symptoms and the occurrence of deaths during ICU stay, which was considered to be a postoperative complication in this study. Note, however, that the occurrence of deaths in the postoperative period was investigated in this study only during ICU stay, while the aforementioned study verified death from all causes up to six months after valve surgery, which may have contributed to the differences ${ }^{(21)}$.

In this study, death occurred among $7.1 \%$ of the patients undergoing valve repair surgery. Since we did not follow up patients during the entire postoperative period, but instead only during the time patients remained in the ICU, as we did not include those who died in the operating room, we cannot compare this study's results to the mortality rates reported in the Brazilian and international literature.
As an example of studies addressing the topic, there is an international study addressing 148 patients aged 70 years old and older who underwent coronary artery bypass grafting and/or valve surgery between 2008 and 2009. The study investigated associations between anxiety reported by patients during the preoperative period assessed by the HADS and postoperative mortality or greater frequency of stroke complications, kidney failure, prolonged ventilation, deep sternal wound infection, or reoperation during the period of postoperative hospitalization. The outcome mortality or complications occurred in $22 \%$ of the patients without anxiety symptoms, in $25 \%$ of the group with potential anxiety, and $55 \%$ of the group reporting anxiety. Intra-hospital mortality in the three groups was 4\%, 6\%, and 9\% respectively. Thus, the authors concluded that significant levels of preoperative anxiety symptoms reported by the patients predicted greater risk of mortality and postoperative complications during hospitalization among elderly patients undergoing cardiac surgery ${ }^{(22)}$.

We also assessed associations between preoperative anxiety and depression symptoms and the patients' sociodemographic characteristics (sex, age, marital status and occupation) and found that women presented a statistically significant ( $p=0.042$ ) higher median for depression symptoms when compared to men. That is, in agreement with the literature, in this study women also presented preoperative depression symptoms more frequently than men ${ }^{(23)}$.

On the other hand, there are studies with results that differ from this study's results. One study failed to find association between preoperative depression symptoms and sex, though a significant association was found between depression symptoms and age; younger patients more frequently experienced depression symptomatology ${ }^{(21)}$. In another study, women also presented statistically significant differences in comparison to men, as they more frequently experienced anxiety before cardiac surgeries ${ }^{(3)}$. No relationship was found in this study between depression symptoms and age, or between sex and anxiety.

Analysis concerning associations between anxiety and depression symptoms and age, marital status, and occupation revealed no differences. One study, though developed with 300 patients undergoing cardiac surgery (all thoracotomy surgeries) verified that female patients, unemployed, without a partner, or younger patients were more likely to experience higher levels of preoperative anxiety symptoms ${ }^{(12)}$. Such a result may be attributed to the size of the sample of patients and the instrument used to investigate the symptoms, which differed in both studies, as well as the specific profile of patients with valve disease addressed in this study. The study 
previously mentioned addressed individuals undergoing cardiac surgeries in general, which reinforces the importance of studying different groups of patients separately.

In regard to the potential relationships between clinical characteristics concerning preoperative length of hospitalization and length of ICU stay and preoperative anxiety and depression symptoms, the correlations found in this study were weak with no statistical significance. These results differ from data reported by a prospective longitudinal study conducted between April and June 2015 in a hospital in the interior of São Paulo, Brazil. It addressed 100 patients who had undergone cardiac surgery (myocardial revascularization and/or valve replacement) and identified that a preoperative length of hospitalization equal to or greater than three days was the main risk factor for preoperative depression ${ }^{(24)}$.

This topic of study is recurrent among patients undergoing cardiac surgery, but we found that different postoperative periods are addressed. Additionally, complications are investigated differently, while there is a lack of consensus concerning the best tool to assess subjective anxiety and depressive symptoms. Additionally, few studies exclusively address patients undergoing valve repair surgeries ${ }^{(2,25)}$.

The fact that patients with valve diseases present a profile very different from those with coronary artery disease needs to be taken into account to obtain a larger amount of scientific evidence that favors the postoperative patient recovery. In this sense, this study's results are relevant for clinical practice. Note we found an association between preoperative depression and postoperative agitation, as well as between being a woman and depression symptoms.

Even though the instrument used to investigate symptoms does not provide a specific diagnosis of mood disorder, it can be useful to identify those patients experiencing anxiety and/or depression symptoms and who, therefore, could benefit from therapeutic interventions intended to make the surgical experiences less traumatic. One study conducted with patients referred to thoracic surgeries intended to assess the diagnostic accuracy of screening tests to discriminate those requiring psychological interventions, verified that the HADS is a brief, simple, well-accepted and appropriate scale, with good diagnostic accuracy for identifying patients requiring psychological treatment ${ }^{(2)}$.

We believe in the importance of assessing preoperative anxiety and depression symptoms in order to improve the stratification of surgical risks, as well as to favor the postoperative recovery of patients undergoing these procedures. Thus, nurses need to understand mood disorders and recognize the impact these symptoms might cause in the pre- and postoperative evolution of valve surgeries. There is also a need to establish a relationship of trust with patients allowing them to share their fears and concerns, as well as provide them with information that concerns their surgical processes. In this context, nurses play an important role, as they are the main agents responsible for providing nursing guidance during the entire perioperative period.

The role of the nursing staff is determinant in minimizing the emotional impact that may result from waiting for a surgical procedure, not only because they provide medications and knowledge, but also because nurses are in a position to favor the establishment of a proper therapeutic relationship ${ }^{(26)}$. Among the tools nurses can use to minimize anxiety and depression in the preoperative period of cardiac surgery, providing information regarding the surgery and properly supporting patients are important strategies ${ }^{(26)}$.

Short screening procedures to measure anxiety, depression or emotional distress are the simplest, fastest, and least invasive way to identify people in need of psychological care ${ }^{(2)}$. Nonetheless, in addition to recognizing anxiety and depression symptoms, nurses are supposed to intervene whenever these symptoms are identified ${ }^{(26)}$. Surgical pre-rehabilitation is an emergent concept that refers to interventions implemented in the preoperative period in order to improve postsurgical results ${ }^{(27)}$. This includes preventive strategies like physical therapy, and pharmacological and non-pharmacological measures to improve results ${ }^{(27)}$. Research confirms that education and the supply of information to patients, as well as organized care that takes into account the patients' preferences, minimize stress before cardiac surgery ${ }^{(3)}$. Additionally, social and familial support, as well as using the patients' religious and spiritual resources, has been shown to decrease preoperative tension ${ }^{(26)}$.

Hospital settings and preoperative care can be very foreign to patients and trigger anxiety and depression symptoms. However, more than assuming what patients are supposed to know, nurses need to identify the particular needs of each patient and perform individualized and equalitarian work by systematizing nursing care. After all, providing integrative patient-centered care is essential to improving quality care delivery.

\section{口CONCLUSION}

An association between preoperative depression symptoms and postoperative agitation during ICU stay was found in this study, as well as an association between preoperative depression symptoms and being a woman.

This study's results reinforce the importance of nurses providing education to patients in the preoperative period, taking into account their emotional states and the fact that information nurses provide can minimize anxiety and 
depression symptoms among patients. These results also support nursing care, as they indicate an easy and fast way to identify patients experiencing preoperative anxiety and depression symptoms. This study also provides information that can aid nurses in understanding and recognizing the relevance of preoperative anxiety and depression symptoms and presents a field for new studies addressing strategies to include all physical, emotional and social dimensions of patients undergoing cardiac surgery in the perioperative nursing care.

The fact that participants were cared for by a single public healthcare facility constitutes a limitation, since patients at higher socioeconomic levels, cared for by private hospitals or by different health services linked to the Brazilian public health system, were not included. Another limitation is the way data were collected. Information regarding most postoperative complications was collected from the patients' medical charts; that is, for complications to be identified during a patient's stay at the ICU, they needed to be recorded in the patients' charts.

New studies could assess complications in longer periods rather than only during ICU stay.

\section{Q REFERENCES}

1. Ghoneim MM, O'Hara MW. Depression and postoperative complications: an overview. BMC Surg. 2016;16:5. doi: https://doi.org/10.1186/s12893-0160120-y

2. Cruzado JA, García VM, Gutiérrez VS, Sarceda IRJ, Olivero CAF, Martín EF et al. Implementing a distress screening program in a thoracic surgery service. Cir Esp. 2019:97(5):275-81. doi: https://doi.org/10.1016/j.cireng.2019.04.008

3. Rosiek A, Kornatowski T, Rosiek-Kryszewska A, Leksowski L, Leksowski K. Evaluation of stress intensity and anxiety level in preoperative period of cardiac patients. BioMed Research International. 2016:1248396. doi: https://doi. org/10.1155/2016/1248396

4. Takagi $H$, Ando $T$, Umemoto T. Perioperative depression or anxiety and postoperative mortality in cardiac surgery: a systematic review and metaanalysis. Heart Vessels. 2017;32(12):1458-68. doi: https://doi.org/10.1007/ s00380-017-1022-3

5. Poole L, Kidd T, Leigh E, Ronaldson A, Jahangiri M, Steptoe A. Psychological distress and intensive care unit stay after cardiac surgery: the role of illness concern. Health Psychol. 2015;34(3):283-7. doi: https://doi.org/10.1037/ hea0000183

6. Tarasoutchi F, Montera MW, Grinberg M, Barbosa MR, Piñeiro DJ, Sánchez CRM et al. Diretriz Brasileira de Valvopatias - SBC 2011// Diretriz Interamericana de Valvopatias - SIAC 2011. Arq Bras Cardiol. 2011 [cited 2019 Jan 05];97(5 supl. 1):1-67. Available from: http://www.scielo.br/pdf/abc/v97n5s1/v97n5s1a01. pdf

7. Siqueira DAA. Doenças estruturais: TAVI e Mitraclip $\oplus^{\circledast}$. In: Silva APL, França AAF, Benetti CFA, editoras. Enfermagem em cardiologia intervencionista. São Paulo: Editora dos Editores; 2018. p. 199-211.
8. Oterhals K, Haaverstad R, Nordrehaug JE, Eid GE, Norekvål TM. Self-reported health status, treatment decision and survival in asymptomatic and symptomatic patients with aortic stenosis in a Western Norway population undergoing conservative treatment: a cross-sectional study with 18 months follow-up. BMJ Open. 2017;7(8):e016489. doi: https://bmjopen.bmj.com/ content/7/8/e016489

9. Kalogianni A, Almpani P, Vastardis L, Baltopoulos G, Charitos C, Brokalaki H. Can nurse-led preoperative education reduce anxiety and postoperative complications of patients undergoing cardiac surgery? Eur I Cardiovasc Nurs. 2016;15(6):447-58. doi: https://doi.org/10.1177/1474515115602678

10. Moraes RCS. Validação do EuroSCORE em valvopatas submetidos à cirurgia cardíaca [tese]. São Paulo (SP): Faculdade de Medicina, Universidade de São Paulo; 2013.

11. Petersen J, Vettorazzi E, Winter L, Schmied W, Kindermann I, Schäfers HJ. Physical and mental recovery after conventional aortic valve surgery. J Thorac Cardiovasc Surg. 2016;152(6):1549-56. doi: https://doi.org/10.1016/j. jtcvs.2016.07.072

12. Fathi M, Alavi SM, Joudi M, Joudi M, Mahdikhani $H$, Ferasatkish R et al. Preoperative anxiety in candidates for heart surgery. Iran J Psychiatry Behav Sci. 2014 [cited 2018 Jan 15];8(2):90-6. Available from: https://www.ncbi.nlm. nih.gov/pmc/articles/PMC4105610/

13. Roohafza H, Sadeghi M, Khani A, Andalib E, Alikhasi H, Rafiei M. Psychological state in patients undergoing coronary artery bypass grafting surgery or percutaneous coronary intervention and their spouses. Int I Nurs Pract. 2015;21(2):214-20. doi: https://doi.org/10.1111/ijn.12234

14. Brucki SMD, Nitrini R, Caramelli P, Bertolucci PHF, Okamoto IH. Sugestões para 0 uso do mini-exame do estado mental no Brasil. Arq NeuroPsiquiatr. 2003;61(3B):777-81. doi: https://doi.org/10.1590/50004-282X 2003000500014

15. Rodrigues HF, Furuya RK, Dantas RAS, Dessotte CAM. Anxiety and depression in cardiac surgery: sex and age range differences. Esc Anna Nery. 2016 [cited 2018 Jan 15];20(3):e20160072. Available from: http://www.scielo.br/scielo. php?pid=S1414-81452016000300217\&script=sci_arttext\&tng=en

16. Gross JL, Ferreira SRG, Oliveira JE. Glicemia pós-prandial. Arq Bras Endocrinol Metab. 2003;47(6):728-38. doi: https://doi.org/10.1590/50004-27302003000 600017

17. Rocha PN, Menezes JAV, Suassuna JHR. Hemodynamic assessment in the critically ill patient. J Bras Nefrol. 2010;32(2):201-12. doi: https://doi. org/10.1590/50101-28002010000200009

18. Botega NJ, Bio MR, Zomignani MA, Garcia C Jr, Pereira WAB. Transtornos do humor em enfermaria de clínica médica e validação de escala de medida (HAD) de ansiedade e depressão. Rev Saúde Pública. 1995;29(5):359-63. doi: https:// doi.org/10.1590/50034-89101995000500004

19. Ajzen I, Fishbein M. Understanding attitudes and predicting social behavior. New Jersey: Prentice-Hall; 1998.

20. Tully PJ, Winefield HR, Baker RA, Denollet J, Pedersen SS, Wittert GA, et al. Depression, anxiety and major adverse cardiovascular and cerebrovascular events in patients following coronary artery bypass graft surgery: a five year longitudinal cohort study. Biopsychosoc Med. 2015;9:14. doi: http://doi. org/10.1186/s13030-015-0041-5

21. Ho PM, Masoudi FA, Spertus JA, Peterson PN, Shroyer AL, McCarthy M Jr et al. Depression predicts mortality following cardiac valve surgery. Ann Thorac Surg. 2005;79(4):1255-9. doi: https://doi.org/10.1016/j.athoracsur.2004.09.047 
22. Williams JB, Alexander KP, Morin JF, Langlois Y, Noiseux N, Perrault LP et al. Preoperative anxiety as a predictor of mortality and major morbidity in patients aged $>70$ years undergoing cardiac surgery. Am J Cardiol. 2013;111(1):137-42. doi: https://doi.org/10.1016/j.amjcard.2012.08.060

23. Poole L, Leigh E, Kidd T, Ronaldson A, Jahangiri M, Steptoea A. The combined association of depression and socioeconomic status with length of postoperative hospital stay following coronary artery bypass graft surgery: data from a prospective cohort study. J Psychosom Res. 2014;76(1):34-40. doi: https://doi.org/10.1016/j.jpsychores.2013.10.019

24. Dordetto PR, Pinto GC, Rosa TCSC. Pacientes submetidos à cirurgia cardíaca: caracterização sociodemográfica, perfil clínico-epidemiológico e complicações. Rev Fac Ciênc Méd Sorocaba. 2016;18(3):144-9. doi: https://doi.org/10.5327/ 21984-4840201625868
25. Leon MB, Smith CR, Mack MJ, Makkar RR, Svensson LG, Kodali SK et al. Transcatheter or surgical aortic-valve replacement in intermediate-risk patients. N Engl J Med. 2016;374(17):1609-20. doi: https://doi.org/10.1056/ NEJMoa1514616

26. Gonçalves, KKN, Silva II, Gomes ET, Pinheiro LLS, Figueiredo TR, Bezerra SMMS. Anxiety in the preoperative period of heart surgery. Rev Bras Enferm. 2016;69(2):397-403 doi: https://doi.org/10.1590/0034-7167.2016690225i

27. Packiasabapathy S, Susheela AT, Mueller A, Patxot M, Gasangwa DV, O'Gara $B$, et al. Guided meditation as an adjunct to enhance postoperative recovery after cardiac surgery: study protocol for a prospective randomized controlled feasibility trial. Trials. 2019;20:39. doi: https://trialsjournal.biomedcentral.com/ articles/10.1186/s13063-018-3103-8

\section{- Corresponding author:}

Hélen Francine Rodrigues

E-mail: hfrodrigues.usp@gmail.com

\section{Associate editors:}

Aline Marques Acosta

Cecília Helena Glanzner

\section{Editor-in-chief:}

Maria da Graça Oliveira Crossetti 